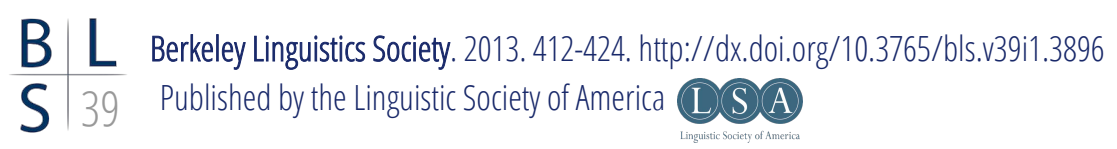

\title{
The Forefinger/Thumb Alternation in Arapaho Pointing: Participation Space as a Frame of Reference
}

\author{
RICHARD A. SANDOVAL \\ University of Colorado, Boulder
}

\section{Introduction}

Pointing is a basic referential resource for human interaction, and Arapaho speakers make full use of its potential. I report on the Arapaho forefinger/thumb pointing alternation for person reference. I argue that the distinction encodes an Arapaho sensitivity to the common space created by interactional co-participants, or the "participation space" (Goodwin 2000). As co-participants often constitute themselves as such by their mutual display of a participation space, this interactional frame of reference is reflected in the Arapaho pointing alternation: Thumb pointing is used for co-participant reference when the participation space is the relevant frame of reference; forefinger pointing is used for person reference when the participation space is not the relevant frame of reference. This functional difference between the two types of pointing is highly motivated by an Arapaho language ideology and the general hand-shape iconicity distinguishing the two points. Together, these two motivators result in forefinger pointing as the highly marked alternate for co-participant reference.

\section{$1 \quad$ General Background}

Arapaho is an American Indian language of the Algonquian family and Great Plains region (Cowell and Moss Sr. 2008). Along with a rich polysynthetic vocal language, Arapaho speakers draw on a rich repertoire of conventional gestures. These gestures largely stem from Plains Indian Sign Language, the pre-20 $0^{\text {th }}$ 
century lingua franca of the Great Plains. Although the forefinger/thumb pointing alternation has not been historically related to Plains Indian Sign Language, the phenomenon is nevertheless exemplary of the conventional gesture that is so characteristic of Arapaho language.

The data I use in this paper comes from the Arapaho Conversational Database (2011) [ACD]. This video-based corpus of Arapaho speakers has over 30 hours of day-to-day interactions amongst the Northern Arapaho on the Wind River Reservation in Wyoming. Thus, although I generally use the term Arapaho in this paper, the claims I maker are specific to the Northern Arapaho and their dialect (there are two closely related dialects). Additionally, all Arapaho speakers are also English speakers, but I have not yet determined whether the forefinger/thumb pointing alternation is associated with Arapaho English too.

\section{$2 \quad$ Pointing and Interactional Frames of Reference}

In this section, I review research that is relevant to understanding the Arapaho use of participation space as a frame of reference in pointing practices. There are two areas of relevant research. The first looks at how frames of reference are conventionalized in pointing practices. The second involves interactional space as a frame of reference encoded in spoken demonstratives. Taken together, this research supports the Arapaho encoding of an interactional space as a frame of reference in pointing.

Whether used in accordance with spoken resources or not, pointing is one of the primary conventionalized resources through which speakers instantiate one spatial frame of reference or another (Haviland 2000; Levinson 2003; Le Guen 2011). Le Guen (2011) has described the typological situation as one in which the conventionalization of frames of reference in pointing practices only applies to a "transposed" referential condition. The transposed condition is used by speakers who are describing the details of a distant (usually, not-visible) scene. The speaker transposes the reference because the figure (i.e. targeted entity or referent) of the pointing action and the ground (i.e. the spatial features of the scene used to referentially resolve the figure) are not situationally accessible to the speaker or the other interactional participants. For the transposed condition, there are two frame-of-reference types that can be encoded in pointing: An "egocentric" and a "geocentric." Egocentric encoding corresponds to what is typically called a relative frame of reference, and so figure-ground spatial relationships are re-created from the speaker's point of view. Geocentric encoding corresponds to what is typically called an absolute frame of reference, and so figure-ground spatial relationships are based on immutable geographic properties (e.g. cardinal direction, landmarks) and thus preserve actual directions and other orientational features of the involved entities. As the transposed condition is basic to human interaction, the two conventionalized systems are pervasive features of 
language use. However, communities tend to be primarily either egocentric or geocentric encoders.

A big part of Le Guen's (2011) argument is that frame-of-reference conventionalization in pointing is not possible in the non-transposed condition. In this condition, the figure and ground are situationally accessible to the interactional co-participants, and so no frame of reference is needed. Thus, a speaker can use direct pointing to individuate a visible referent, an activity that all communities have in common. The author argues that in this non-transposed condition, the "origo" (or source of the pointing action) is always the speaker's body, and so there is no variable in the non-transposed condition making alternate frames of reference possible. However, Hanks (1990) argues that the origo is also variable in the non-transposed condition. Different origo configurations, then, can also be encoded in referential forms. The origo can be the speaker's body or it can be the space embodied by the interactional co-participants (among other possibilities). Thus, a referential act has the potential to highlight both a referent and an origo. The problem with this notion, though, is that Hanks (1990) was discussing the potential of spoken referentials, and there is no physical attachment between a body and a spoken referential as there is with pointing.

Enfield's (2003) work on Lao demonstratives, however, brings us a little closer to how an interactional space might be encoded as a frame of reference. $\mathrm{He}$ shows that with the two Lao demonstratives (similar to here vs. there or this vs. that), when there is a contextual possibility that either one is relevant, their opposing values will be based on a contextually relevant 'here space,' which is often the space embodied by the interactional co-participants (as opposed to a space based on the speaker). In general, such interactional spaces are crucial components of human interaction, as they are dynamically constructed by coparticipants of an interaction, mutually positioning and orienting their bodies and gestures with respect to each other and other material in their immediate environment (see also Kendon 1990; Goodwin 2000; Mondada 2009). According to Enfield (2003), a here demonstrative will thus index the 'here-space' of the relevant interactional space, whereas the there demonstrative will index the 'nothere space' of the relevant interactional space. The referent of either demonstrative is indicated through direct pointing, and so a demonstrative and point work together to resolve some referent. Thus, what is indicated by one demonstrative or the other is not a referent itself, but a ground on which a referent is foregrounded. Interactional spaces, then, can also act as frames of reference, but they apply to the non-transposed condition.

For Arapaho speakers, there is a particular sensitivity to one type of interactional space: "participation space" (Goodwin 2000). A participation space is the generic space that is managed by the bodies of interactional co-participants in order to display mutual engagement. In (1), we see a typical Arapaho participation space. 
(1) Side-by-side Arapaho participation space; ACD file 25A

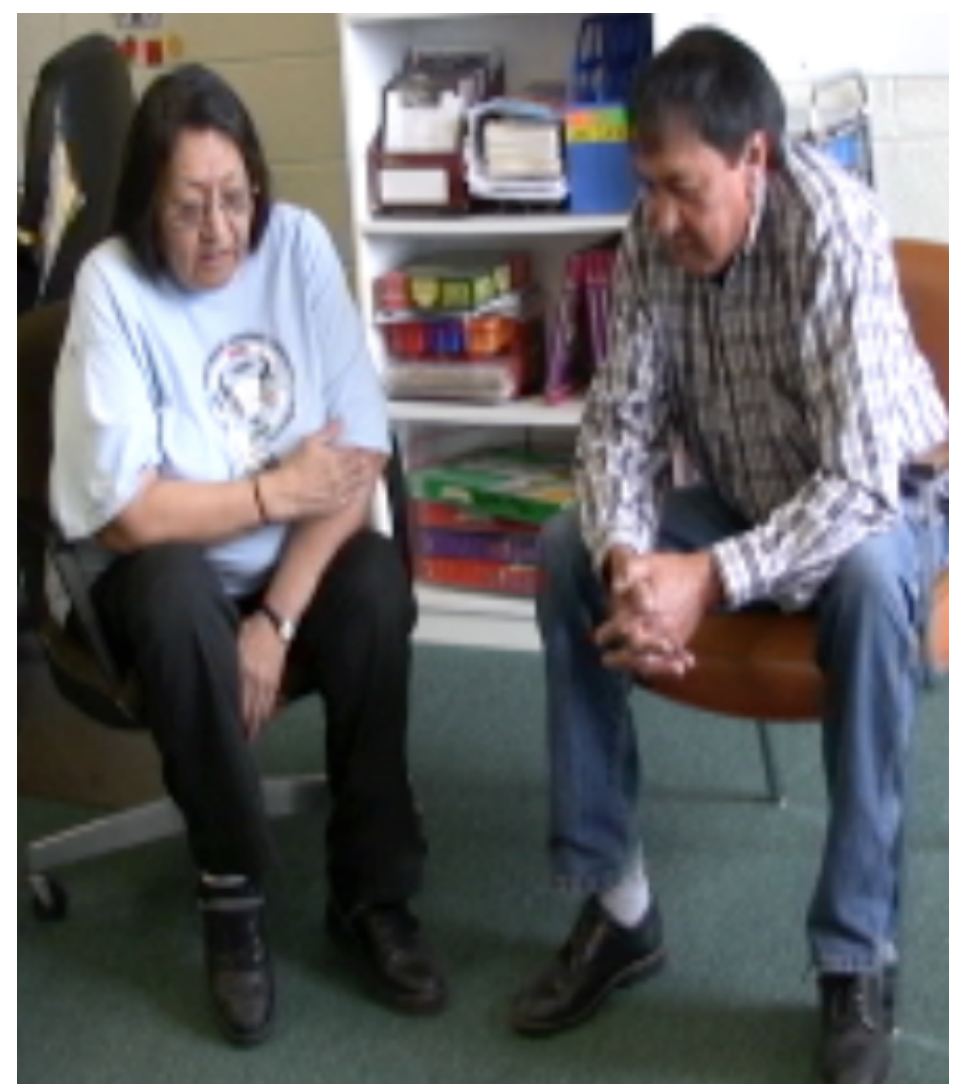

The co-participants in this interaction have seated themselves in a side-by-side manner, creating a sort of arc so that they appear to be a segment of a large circle. This participation arrangement is typical of Arapaho interactions. Characteristic of participation spaces in general, it displays symmetry (cf. Kendon 1990). For Arapaho interaction, this symmetry translates to a center point that is equidistant from the participants. An interactant will gaze at this point as sort of a neutral or inactive state of interaction, as the participants in (1) are doing. Within this space, gestures and other bodily actions are at least within the peripheral vision of coparticipants, allowing for ease of co-participant coordination.

Participation spaces are important not just for the visual coordination of interaction, but also as a means for one to demonstrate engagement in the ongoing interaction (i.e. co-participation). This use of the participation space is especially relevant when there are others present who are not engaged in the ongoing interaction. For example, in (2) and (3), two participation spaces are created, one after the other. 
(2) Exclusive participation space; ACD file $14 \mathrm{a}$

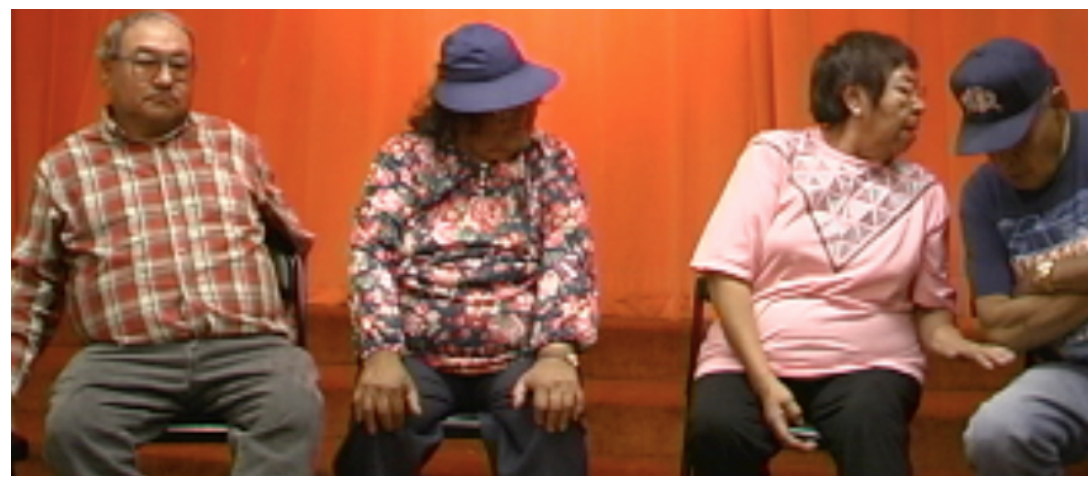

(3) Inclusive participation space; ACD file $14 \mathrm{a}$

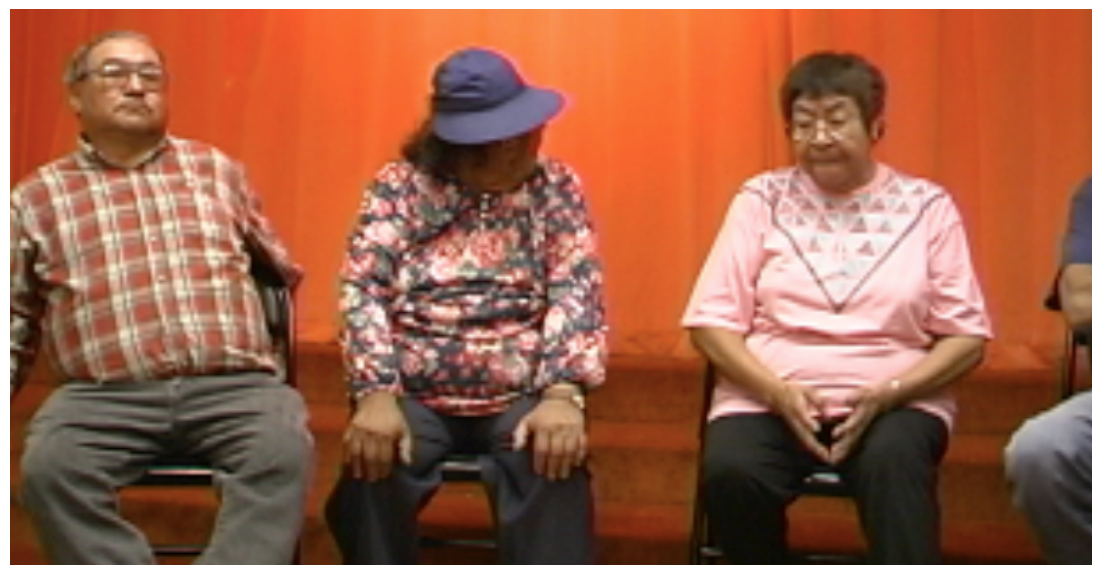

The woman in the pink and her husband are clearly creating an exclusive participation space with respect to the others on the stage. Moments later, a more inclusive and generic side-by-side arrangement is resumed, and a different participation space is thus created.

Similar to what Enfield (2003) found in his study Lao demonstratives, Arapaho speakers use the participation space as a frame of reference. However, for the Arapaho, the participation space is indexed not through a pair of spoken demonstratives but in a pointing alternation. The next section gives relevant background on Arapaho pointing, and the encoded sensitivity to participation space.

\section{The Pointing Sensitivity to Participation Spaces}

In this section, I introduce the forefinger/thumb pointing alternation as it demonstrates a sensitivity to person reference within a common participation space (i.e. for co-participant reference). The sensitivity is reinforced by a 
language ideology in Arapaho concerning the appropriateness of forefinger pointing. The concern with forefinger pointing means that other types of pointing, such as thumb pointing, are not necessarily noticeable as pointing activities in Arapaho. Thus, as forefinger points are marked for co-participant reference, thumb points are not.

Arapaho speakers, like those of many other Native American communities, have a proscription against pointing. The Arapaho proscription, however, is more of a soft proscription, as there is a pervasive amount of all types of pointing amongst Arapaho speakers in interaction. A qualification, then, is needed to understand how there can be a proscription against pointing amongst those who take full advantage of pointing as a resource for interaction. First, the proscription does not extend to all types of pointing. Rather, for Arapaho speakers, pointing is ideologically most salient when it takes the form of a forefinger point. And, although professional analysts may consider other types, such as lip pointing, open-hand pointing, and thumb pointing, such gestures are not necessarily noticeable as pointing in Arapaho. Forefinger pointing is thus more of an onrecord pointing activity in Arapaho than are other types of pointing.

In practice, the proscription against forefinger pointing only applies to the domain of person reference. It is never problematic to point at objects or places with a forefinger. Further, the proscription only applies to persons who are fellow interactional co-participants of the pointing person. Thus, forefinger pointing is heavily marked when the pointing person and the pointed-at person are costructuring a participation space. More specifically, a forefinger point at a coparticipant works to negate the participation space as a relevant frame of reference for the point.

Thus, a participation space has two important qualities that are salient to marked actions involving reference to a co-participant, and Arapaho speakers use the forefinger point as a resource for these actions. First, as I discussed in the prior section, co-participants generally structure participation spaces so that each member of the interaction has equal access to the visible properties of the interaction. In order for basic interaction to work, this type of equality or social symmetry must be maintained (Heritage 2008). However, in the marked action of giving a command or a directive, a social asymmetry (or power differential) in the interaction is implied, as the director attempts to control the directed. For Arapaho speakers giving directives, the forefinger point works to divorce the commanding action from the interactional equality indexed by the participation space.

The second quality of a participation space that is salient to marked actions involving co-participant reference is its use as a referential anchor. As previously discussed, the participation space is very important for the concept of 'here' for interactional co-participants. That is, the participation space is the most relevant situational anchor, and so when a speaker is transposing a reference onto a distant place or otherwise making a space outside of the participation space relevant, the 
speaker must first negate the relevance of the participation space. Further, in the case that a co-participant is a character or in some other way associated with a transposed scene or distant place, a forefinger point at the co-participant negates the participation space. Thus, the transposed scene or distant place is made referentially relevant to the action. The forefinger thus works in this way by making the referred-to person's interactional identity a matter of the transposed scene or distant place, as opposed to making it a matter of the person's role in the "participation framework," such as hearer and recipient (Goodwin and Goodwin 2004). In (5), a speaker uses a forefinger to point at a co-participant for such an action.

(4) Forefinger point for place reference; ACD file 24b, 4:34

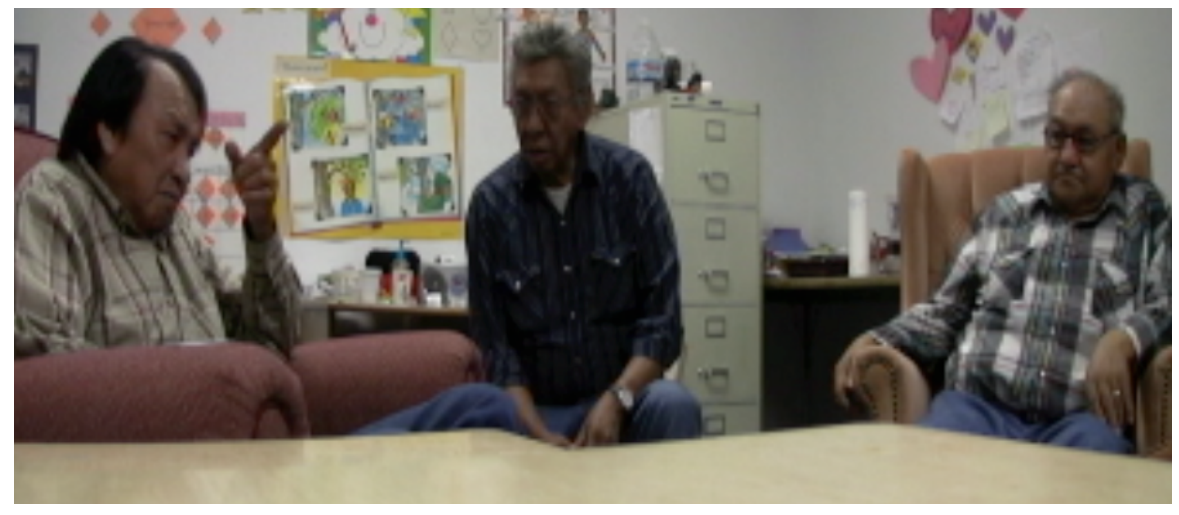

(5) Forefinger point for co-participant reference; ACD file 24b, 4:42

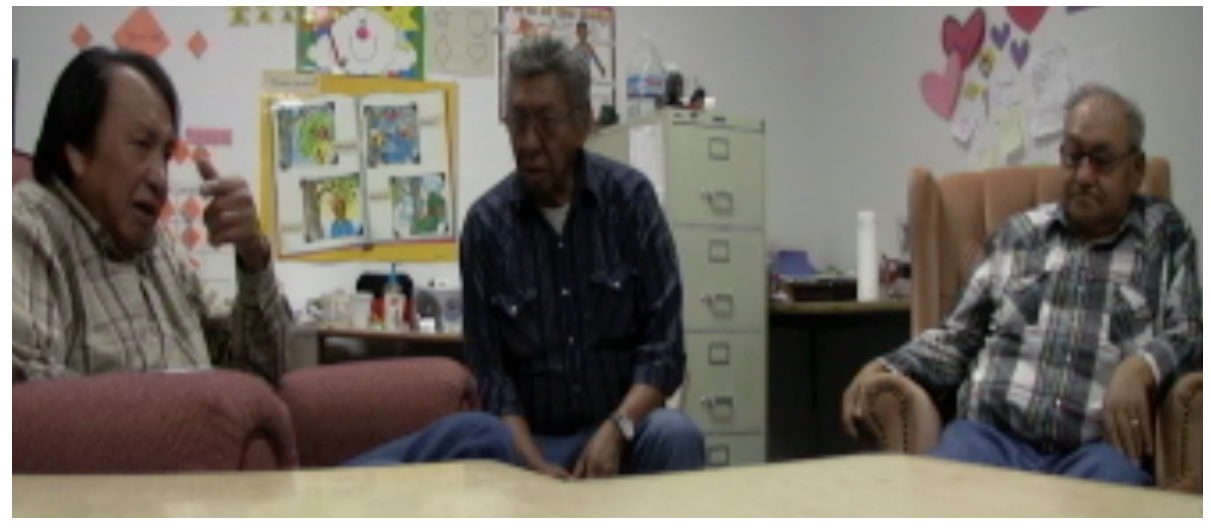

(6) nee'ee- nee'ee- nee'eeteihi-t that.is- that.is- that.is.where.X.is.from-3.S 'That's where she is from'

In (4), we see that the speaker is first pointing to Boulder, Colorado, in reference 
to where one of the co-participants is going to school. The referred to coparticipant is a woman sitting to the speaker's right and out of the camera view. In (5) he points at this woman and explicitly states that she is from Boulder, as we see in (6). The forefinger point works to associate the woman with Boulder, as the speaker is in the process of developing the woman's association with another person through the mutual involvement that these two persons have with the school in Boulder. Thus, the focus here can be paraphrased as Boulder, the place where the woman is from as opposed to the woman, who is from Boulder. The forefinger point makes Boulder, and not the participation space, referentially relevant to the woman's interactional identity in this moment.

Thus, it is because of the social implications of using the forefinger point for person reference within the participation space (i.e. creating social asymmetries and distance from the 'here') that there is a proscription against pointing. However, when a speaker makes general reference to a co-participant, a pointing action is often necessary. So, in avoidance of forefinger pointing in such situations, the Arapaho practice is to use a thumb point. Again, a thumb point is technically a point, but in accord with Arapaho ideology a thumb point is not noticeable as a point in the same way that a forefinger point is.

The following sequence demonstrates the sensitivity of the forefinger/thumb pointing alternation for co-participant person reference. The situation involves a speaker who refers to someone next to her with first a forefinger point (see (7)) and then a thumb point (see (9)). Four people are seated side-by-side on a stage preparing to tell traditional Arapaho stories to an audience. The woman in the pink shirt and her husband turn inward toward one another. She speaks into his ear, instructing him to tell the audience that the woman in the hat will speak first. The woman in the pink shirt points with a forefinger at the woman in the hat on nehe' in (7) and (8).

(7) Forefinger used for non-co-participant reference; ACD file 14a, 0:10

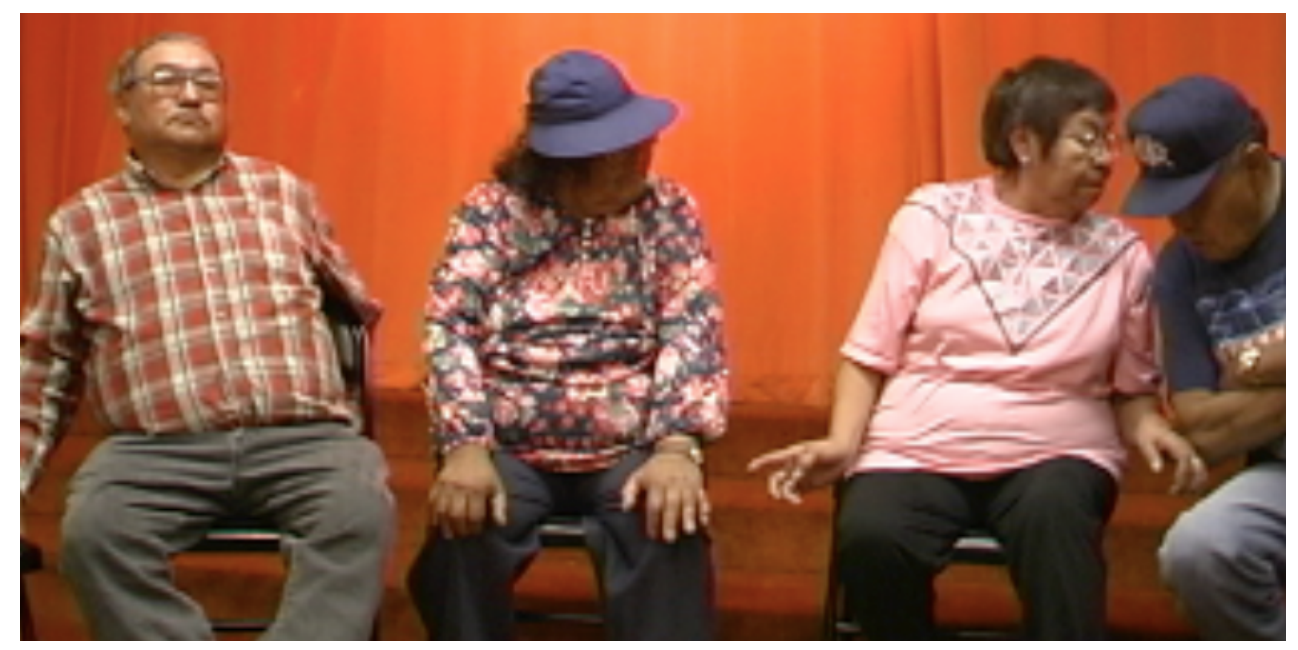



(8) he3eb-ei'towuun-inee ne'-P tell.s.o.-3.IMPER then-pause this FUT-begin-do-3.S

'Tell them that this one will start'

In their coordination, the woman in pink and her husband's participation space excludes the woman in the hat, and thus the woman in the hat is referred to with a forefinger point, as an individual distinct from the ongoing interaction. Seconds later, the woman in pink disengages from the exclusive arrangement with her husband by facing her body outward to coordinate with the others. Again, the side-by-side arrangement is not just a product of this cultural performance, it is also rather typical of Arapaho interactions. Signaling this change of participation space, the woman in pink briefly makes eye contact with the woman in the hat. At that moment, the husband vocalizes some confusion, and so the woman in pink reinforces her initial instruction to him in a repair sequence. This time, the woman in pink uses a thumb point at the woman in the hat on neh'eeno in (9) and (10).

(9) Thumb point for co-participant reference; ACD file 14a, 0:18

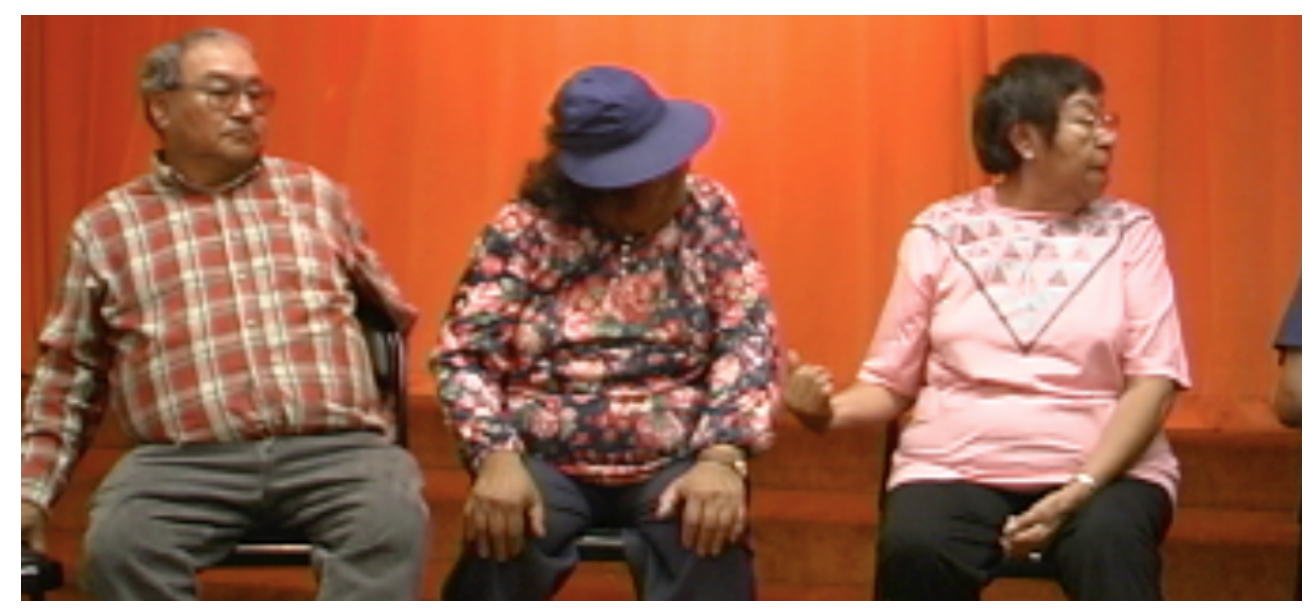
(10) hiiko neh'eeno heet-ne'-cesisi-too-t
no this FUT-then-begin-do-3.S

'No, her, she's the one who will start'

In (9) we see that the woman in pink turns her head to her husband and not her whole body, maintaining the inclusive participation space with the woman in the hat. The thumb point and not the forefinger point is thus used to refer to the woman in the hat.

The Arapaho forefinger/thumb pointing alternation, then, is reinforced by the soft proscription against pointing and thus demonstrates a culturally specific sensitivity to participation spaces. Specifically, these spaces are primary frames of 
reference for situational distinctions in person status made through basic referential acts (cf. Hanks 1990; 2005). The next section discusses more about the forefinger/thumb alternation, especially as it relates to other properties of the Arapaho language.

\section{The Relation of Form and Function in the Alternation}

The following section gives further detail on the forms and functions involved in the forefinger/thumb pointing alternation. While both forefinger and thumb pointing constitute pointing in a technical sense, thumb pointing has qualities that make it particularly salient as a functional pointing resource, but one that is nevertheless unnoticeable as such from an Arapaho perspective.

Technically defined, pointing is a movement of the body that is spatially directed, and recognizably so by a co-participant. Both forefinger pointing and thumb pointing are thus types of pointing in this sense. In many languages, it is apparent that the difference between these two pointing hand shapes is a matter of anatomical convention, the thumb used for back and side pointing, the forefinger used for forward pointing. However, in Arapaho, there are instances of both forward thumb pointing as well as behind-the-back forefinger pointing (cf. Wilkins 2003). This contrasting distribution of the forefinger and thumb morphologies thus underscores the functional conditioning of the alternation.

Further, the differential functions of these two points are in large part motivated by their forms. Forefinger points have the forefinger extended and the rest of the fingers at least partially closed. The line made from the base of the forefinger to the tip of the forefinger determines the directional aim of a forefinger point. Forefinger points thus maximize visual precision in this way. With a thumb point, the thumb is protruding relative to the other fingers, which are at least slightly closed. Different from forefinger pointing, however, the thumb need not-and is often not-the source of directionality in a thumb point. In a thumb point, directionality is more often a matter of hand movement. The protruding thumb thus defines the hand shape but not necessarily the means of resolving direction. This is not much of a surprise given that thumbs are generally not as straight as forefingers. This difference in hand-shape form and use highlights how the precision of the forefinger point makes it a more exemplary and noticeable type of pointing.

However, the difference in hand-shape form and use are also iconic of the informational qualities of these points (cf. Enfield, Kita, and De Ruiter 2007). This iconicity is important for understanding how the thumb point has come into position as the unmarked form for co-participant person reference. The best display of the underpinnings of this iconic relationship occurs in the use of the forefinger/thumb pointing alternation for non-person reference (cf. Kendon and Versante 2003). In this domain, the forefinger point is generally used to 


\section{The Forefinger/Thumb Alternation in Arapaho Pointing}

individuate places and objects that are well defined from the perspective of the pointing person and other co-participants. In the visual range, things that can be foregrounded and focused on as well-defined entities are referred to with a forefinger point. This includes a wide range of things. At close range it can include objects such as chairs and trees, while at a more distant range it could include a building. It would not include, however, a building that a speaker is standing right next to, for example, as the building could not be focused on as a well-defined entity from that person's perspective. Places that are out of the visual range are also treated with a forefinger point if they can be conceived of as singularities from the perspective of participants. For example, a town that is twenty miles away would be identified by pointing with a forefinger to its most central area. The forefinger is thus used to individuate entities, whether within view or within the broader landscape that is commonly understood by coparticipants. With forefinger points, then, a participant doesn't discriminate whether an entity is visible or not, only whether or not it can be visually foregrounded.

In non-person reference, the thumb point is used to refer to backgrounded spaces, especially regions and entities that are blurred from the perspective of coparticipants. Because of this, thumb points are usually used to refer to spaces that are not too distant from participants. For example, a thumb point is used to refer to near patches of land or a broad area of a locality. Additionally, if one is making reference to a building or its interior space, they will use a thumb point in the case that they are standing next to it. Such spaces are either too close to be individuated or are too close to have well-defined centers from the perspectives of participants.

In sum, forefinger pointing is more precise, and this precision iconically motivates its use to foreground entities that can be perceived (or construed) as well defined and bounded from the co-participant perspective. In contrast, thumb pointing is less precise, and this low precision iconically motivates its use to display an area as less defined or out of focus, a region from the perspective of co-participants. Thus, thumb pointing in Arapaho is essentially a low-fidelity means of reference.

In the domain of co-participant reference, this low-fidelity nature reinforces thumb pointing as the appropriate alternative to forefinger pointing. One can thumb point in the general direction of a person without the pointing action itself being noticeable as a point. Additionally, for co-participant reference, the iconically-motivated informational difference between forefinger and thumb pointing is underscored by the speech that co-occurs with each type of pointing. Forefinger pointing often co-occurs with the demonstrative nehe', which is used as the general demonstrative for person reference. Thumb pointing, however, very often co-occurs with the demonstrative nehe'eeno, which is also a demonstrative for person reference, but it has the added meaning that the referent is moving 
around or otherwise difficult to identify with clarity. It is only in the domain of co-participant reference that nehe'eeno is regularly used to refer to persons who are not difficult to identify with clarity. Thus, the low-fidelity informational nature of thumb pointing is supported by the demonstrative it regularly occurs with. However, whether it co-occurs with the demonstrative or not, such regular "affiliation" (Schegloff 1984) between the two forms strengthens the use of thumb pointing as the unnoticeable pointing resource for co-participant reference.

\section{Conclusion}

Although participation spaces are essential to human interaction, Arapaho speakers demonstrate a particular sensitivity to it. This sensitivity is manifest in how participation spaces are used in pointing practices as frames of reference for referring to co-participants and others in the vicinity of the interaction. A speaker uses a forefinger point to individuate someone outside of the participation space (i.e. a non-co-participant). A speaker also uses a forefinger point to refer to a coparticipant for situations in which the participation space is not the momentary relevant frame of reference. Such a use, however, is marked, and the markedness is reinforced by an Arapaho proscription against pointing in certain contexts. For co-participant reference, speakers use thumb pointing. Because thumb pointing is iconic of low information, thumb points are generally unnoticeable as pointing activities in Arapaho, and so the use of a thumb point does not fracture the interactional equality indexed by the structure of the participation space. The forefinger/thumb pointing alternation for co-participant reference in Arapaho thus serves to maintain the integrity of participation space as a primary frame of reference.

\section{References}

Arapaho Conversational Database 2011 Data collected and processed by Dr. Andrew Cowell, University of Colorado, 2007-11. Funded by Hans Rausing ELDP. Deposited at ELAR Archive, SOAS, University of London, Sept. 2011.

Cowell, Andrew, and Alonzo Moss Sr. 2008. The Arapaho Language. Boulder, CO: University of Colorado Press.

Enfield, N. J. 2003. Demonstratives in Space and Interaction: Data from Lao Speakers and Implications for Semantic Analysis. Language 79(1):82-117.

Enfield, N. J., Sotaro Kita, and J.P. De Ruiter. 2007. Primary and Secondary Pragmatic Functions of Pointing Gestures. Journal of Pragmatics 39:17221741.

Goodwin, Charles. 2000. Action and Embodiment within Situated Human Interaction. Journal of Pragmatics 32:1489-1522.

Goodwin, Charles, and Marjorie Harness Goodwin. 2004. Participation. In A. 
Duranti, ed. A Companion to Linguistic Anthropology, Malden, MA: Blackwell. Hanks, William F. 1990. Referential Practice: Language and Lived Space among the Maya. Chicago: The University of Chicago Press.

Hanks, William F. 2005. Explorations in the Deictic Field. Current Anthropology 46 (2):191-220.

Haviland, John B. 2000. Pointing, Gesture Spaces, and Mental Maps. In D.

McNeil, ed., Language and Gesture, Cambridge: Cambridge University Press.

Heritage, John. 2008. Conversation Analysis as Social Theory. In B. Turner, The

New Blackwell Companion to Social Theory, Oxford: Blackwell.

Kendon, Adam. 1990. Conducting Interaction: Patterns of Behavior in Focused Encounters. Cambridge: Cambridge University Press.

Kendon, Adam, and Laura Versante. 2003. Pointing by Hand in "Neapolitan". In S. Kita, Pointing: Where Language, Culture, and Cognition Meet, Mahwah, NJ: Lawrence Erlbaum.

Le Guen, Oliver. 2011. Modes of Pointing to Existing Spaces and the Use of Frames of Reference. Gesture 11(3):271-307.

Levinson, Stephen C. 2003. Space in Language and Cognition: Explorations in Cognitive Diversity. Cambridge: Cambridge University Press.

Mondada, Lorenza. 2009. Emergent Focused Interactions in Public Places: A Systematic Analysis of the Multimodal Achievement of a Common Interactional Space. Journal of Pragmatics 41:1977-1997.

Schegloff, Emanuel A. 1984. On Some Gestures' Relation to Talk. In J. M. Atkinson and J. Heritage, eds., Structures of Social Action, Cambridge: Cambridge University Press.

Wilkins, David. 2003. Why Pointing With the Index Finger Is Not a Universal (in Sociocultural and Semiotic Terms). In S. Kita, ed., Pointing: Where Language, Culture, and Cognition Meet, London: Lawrence Erlbaum Associates.

Richard A. Sandoval

University of Colorado, Boulder

Department of Linguistics

Hellems 285

Boulder, CO 80309-0295

Richard.Sandoval@Colorado.edu 